\title{
Factors Affecting EWS-FLI1 Activity in Ewing's Sarcoma
}

\author{
David Herrero-Martin, Argyro Fourtouna, Stephan Niedan, Lucia T. Riedmann, \\ Raphaela Schwentner, and Dave N. T. Aryee
}

Children's Cancer Research Institute, St Anna Kinderkrebsforschung, 1090 Vienna, Austria

Correspondence should be addressed to David Herrero-Martin, david.herrero@ccri.at

Received 15 July 2011; Revised 31 August 2011; Accepted 31 August 2011

Academic Editor: Alessandro Gronchi

Copyright (C 2011 David Herrero-Martin et al. This is an open access article distributed under the Creative Commons Attribution License, which permits unrestricted use, distribution, and reproduction in any medium, provided the original work is properly cited.

Ewing's sarcoma family tumors (ESFT) are characterized by specific chromosomal translocations, which give rise to EWS-ETS chimeric proteins. These aberrant transcription factors are the main pathogenic drivers of ESFT. Elucidation of the factors influencing EWS-ETS expression and/or activity will guide the development of novel therapeutic agents against this fatal disease.

\section{Introduction}

ESFT comprise a group of undifferentiated, highly malignant small blue round-cell pediatric tumors. They are genetically characterized by EWS-ETS gene rearrangements affecting EWSR1 and genes of the ETS-family of transcription factors, predominantly FLI1 characterizing $85 \%$ of cases [1]. Numerous efforts have been undertaken in the last three decades to explore the functional role of EWS-FLI1 in tumor pathogenesis. EWS-FLI1 has been identified as the main genetic factor of malignancy in $\operatorname{ESFT}[2,3]$ and it is also causal in the pathogenesis of ESFT from its cellular types of origin [4-6]. It has been widely documented that this chimeric protein acts both as a transcriptional activator and repressor of similarly sized sets of target genes [7, 8]. While most mechanistic studies have concentrated on the identification and description of downstream EWS-FLI1 regulated genes, this paper focuses on currently known factors influencing EWS-FLI1 activity up- and downstream of the fusion protein and consequently modulate its target gene expression.

\section{Structure and Posttranslational Modifications Affecting the Transcriptional Activity of EWS-FLI1}

Since, due to its tumor-specific expression, EWS-FLI1 protein is considered an ideal therapeutic target [71], significant efforts have been made to understand the function of this fusion protein. Knowledge about the detailed EWS-FLI1 protein structure would be extremely helpful to analyse and predict its DNA-binding properties as a basis for a better understanding of the EWS-FLI1 transcriptional network and for the development of inhibitory modalities with therapeutic promise.

EWS-fusion proteins contain at least the N-terminal 7 exons of EWS comprising the EWS activation domain (EAD). The EAD structure consists of multiple degenerate hexapeptide repeats (consensus SYGQQS) with a conserved tyrosine residue. However, systematic mutagenesis of the EAD revealed that the overall sequence composition and not the specific sequence of the degenerate hexapeptide repeat confer EAD activity [72]. The C-terminal portion of EWS-FLI1 consists of a COOH-terminal domain as well as an ets-type winged helix-lop-helix DNA-binding domain (DBD). Arvand et al. suggested that, in addition to the EAD and DBD domains, the COOH-terminal FLI1 domain contributes to promote cellular transformation [73]. Mutation analysis of the EWS-DBD revealed that EWS-FLI1, apparently, not only induces DBD-dependent but also DBDindependent oncogenic pathways, suggesting that EWS-FLI1 interacts with other gene regulatory factors or complexes [74].

Transcriptional regulation is tightly controlled by transcription factor binding to regulatory regions within DNA as well as recruitment of cofactors. Although ETS transcription 
factors bind predominantly as monomers to a GGAA/T core motif in promoter or enhancer regions of their target genes, functional interaction between ETS proteins and other factors is crucial to enhance or modulate DNA binding [75]. Even though EWS-FLI1 possesses protein interaction domains such as SH2 or PDZ, the identified intrinsically disordered protein regions may facilitate protein-protein complexes as explained in the next chapter [76].

However, transcriptional control also involves complex upstream signaling pathways that converge on the posttranslational modification of transcription factors and their interacting cofactors. Phosphorylation and glycosylation are two examples of posttranslationally modifying mechanisms affecting EWS-FLI1 activity. The EWS portion of about 20\% of EWS-FLI1 fusion proteins (those that retain EWS amino acids 256 to 285) contains a conserved calmodulin-binding motif within the IQ domain with a phosphorylated internal Protein Kinase C recognition site at Ser 266 [9]. Mutation of this residue was enough to significantly reduce DNA binding of EWS-FLI1 in vitro $[9,10]$. Furthermore, EWS and EWSFLI1 are phosphorylated at Thr 79 in the N-terminal domain in response to DNA damage or mitogens [11]. Glycosylation is the enzymatic process that attaches glycans to proteins, lipids, or other organic molecules [77]. EWS-FLI1 was found to undergo O-linked beta- $\mathrm{N}$-acetylglucosaminylation (OGlcNAcylation). This modification seems to be reciprocally related to phosphorylation and to influence the transcriptional activation propensities of the fusion protein [12]. In addition, $\mathrm{N}$-linked glycosylation was described as essential to sustain ESFT cell growth. Interestingly, inhibition of $\mathrm{N}$-linked glycosylation decreased the expression of EWSFLI1 correlating to growth arrest [13]. The highly decreased expression levels of EWS-FLI1 observed after treatment with HMG-CoA reductase inhibitors (i.e., lovastatin) or N-linked glycosylation inhibitors (i.e., tunicamycin) were found to be due to the instability of de novo-synthesized fusion protein $[13,52]$. Lovastatin triggered differentiation and induced apoptosis without causing cell cycle arrest through the loss of an RB-regulated G1 checkpoint [52]. Although EWS-FLI1 contains four potential sites for this type of posttranslational modification, no evidence for direct Nglycosylation of the fusion protein could be obtained. Therefore, an indirect functional interaction involving other keyplayer glycoproteins has been proposed [13]. Since blockage of N-linked glycosylation also leads to inactivation of IGF-1R signaling by inhibiting translocation to the cell surface [14], and since IGF-1R activity is essential to EWSFLI1 expression (discussed in Section 4), inactivation of this pathway may at least partially explain why inhibition of N-linked glycosylation leads to reduced expression of the fusion protein. However, further investigations are required to test this hypothesis (summarized in Table 1).

\section{Direct EWS-FLI1 Protein Interactions}

Biochemical purification and analysis identified EWS-FLI1 as an intrinsically disordered protein $[72,78]$. Intrinsically disordered proteins are defined by their lack of a stable structure when isolated. A characteristic composition of amino acids prevents these proteins from forming singular, fixed structures thereby enabling them for rapid complex formation and dissociation with relatively high specificity and low affinity [76]. As no direct enzymatic activity has been ascribed to EWS-FLI1, it is necessary to identify interaction partners of the fusion protein in order to learn more about the functional pathways in which it is involved and how to modulate them therapeutically.

EWS-FLI1 is generally perceived as a transcriptional activator [79-81]. Consistent with its transcriptional activator function, EWS-FLI1 associates with several proteins of the basal transcription machinery. Among them are RNA polymerase II [15] and its core subunit hsRBP7 [16-18], CREB-binding protein (CBP)/p300 [19], and RNA helicase A (RHA) [22]. The interaction with (CBP)/p300 was demonstrated to be involved in the regulation of several bona fide EWS-FLI1 targets like p21 [82] or matrix metalloproteinase (MMP-1) [83]. RHA is a modulator of transcription as it interacts with $\mathrm{CBP} / \mathrm{p} 300$ and RNA polymerase II. Interruption of this interaction induces apoptosis in vivo and in vitro, a potential novel therapeutic strategy $[22,53]$. Interaction with the putative tumor suppressor BARD1, that associates with the breast cancer susceptibility gene BRCA1, links EWS-FLI1 with proteins involved in genome surveillance, DNA repair, and checkpoint control [23]. It is likely that target site selectivity of EWS-FLI1 is mediated via interaction with other sequence specific transcription factors. Such an interaction has been described for FOSJUN dimers, which bind to AP1 sequences synergizing with EWS-FLI1 in the regulation of a subset of EWS-FLI1 target genes including uridine phosphorylase [24]. Recent in silico analyses reveal a significant enrichment of E2F binding sites in EWS-FLI1 upregulated genes suggesting an important role of the E2F family of transcription factors in EWSFLI mediated transcriptional regulation [8]. Whether EWSFLI1 actually physically interacts with E2Fs to accomplish upregulation of the affected genes or merely binds alongside E2F transcription factors remains to be elucidated.

In addition to transcriptional activation, an at least equal number of genes are downregulated by EWS-FLI1 as are upregulated [25]. One explanation for this fact is that some of the upregulated EWS-FLI1 targets are transcriptional repressors as exemplified by NKX2.2, a directly EWS-FLI1activated target which functions as a transcriptional repressor $[84,85]$. Another target of EWS-FLI1, NR0B1, not only acts as a transcriptional regulator downstream of EWS-FLI1 but also has recently been shown to interact physically with EWS-FLI1 to influence gene expression thereby contributing to Ewing's sarcoma oncogenesis [25]. Due to interaction with several RNA processing proteins including the small nuclear ribonucleoprotein (snRNP) U1C [86], EWS-FLI1 activity has not only been linked to RNA transcription but also to splicing [26, 87]. U1C plays a critical role in the initiation and regulation of pre-mRNA splicing as part of the U1 small nuclear ribonucleoprotein and commits pre-mRNAs to the splicing process [88]. Interestingly, forced U1C expression was demonstrated to modulate dose-dependently the transcriptional transactivation activity of EWS-FLI1 in vitro 
TABLE 1: Factors influencing EWS-FLI1 activity and/or expression.

\begin{tabular}{|c|c|c|}
\hline \multicolumn{3}{|l|}{ Posttranslational modifications } \\
\hline Phosphorylation & DNA binding, response to DNA damage and mitogens & {$[9-11]$} \\
\hline Glycosylation & Transcriptional activation, cell growth, link with IGF-1 signaling & {$[12-14]$} \\
\hline \multicolumn{3}{|l|}{ Direct protein-protein interactions } \\
\hline RNA polymerase II & Basal transcription machinery & {$[15]$} \\
\hline hsRBP7 & Basal transcription machinery & {$[16-18]$} \\
\hline Creb-binding protein $(\mathrm{CBP}) / \mathrm{p} 300$ & $\begin{array}{l}\text { Basal transcription machinery, regulation of EWS-FLI1 targets like } \\
\text { p21 or MMP-1 }\end{array}$ & [19-21] \\
\hline RNA helicase A (RHA) & Modulator of transcription & {$[22]$} \\
\hline BARD1 & $\begin{array}{l}\text { Putative tumor suppressor; genome surveillance, DNA repair and } \\
\text { checkpoint control }\end{array}$ & [23] \\
\hline FOS-JUN dimers & $\begin{array}{l}\text { Binding to AP1 sequences synergizing with EWS-FLI1, regulation of } \\
\text { uridine phosphorylase }\end{array}$ & {$[24]$} \\
\hline NR0B1 & Transcriptional regulator downstream of EWS-FLI1 & {$[25]$} \\
\hline small nuclear ribonucleoprotein (snRNP) U1C & pre-mRNA splicing & {$[26]$} \\
\hline EWS & Functional consequences of this heterodimerization unknown & {$[20]$} \\
\hline \multicolumn{3}{|l|}{ Factors indirectly affecting EWS-FLI1 activity } \\
\hline p53 and INK4A pathways & Loss of each one stabilizes EWS-FLI1 & {$[27-33]$} \\
\hline Hypoxia & Apoptosis resistance via HIF, chemotherapy failure, angiogenesis & [34-37] \\
\hline IGF-1/IGF-1R pathway & $\begin{array}{l}\text { EWS-FLI1 mediated cellular transformation, proliferation and } \\
\text { survival }\end{array}$ & [38-45] \\
\hline bFGF & Triggers EWS-FLI1 expression in serum-depleted ESFT cells & {$[46]$} \\
\hline BLCAP & Ectopic overexpression decreases EWS-FLI1, apoptosis & {$[47]$} \\
\hline \multicolumn{3}{|l|}{ miRNAs } \\
\hline $\operatorname{miR}-145$ & EWS-FLI1 repressed miRNA, regulatory feedback loop & {$[48,49]$} \\
\hline $\begin{array}{l}\text { miR-100, miR-125b, miR-22, miR-221/222, } \\
\text { miR-271 and miR29a }\end{array}$ & EWS-FLI1 repressed miRNAs, targets in IGF signalling pathway & {$[50]$} \\
\hline let-7 family & EWS-FLI1 repressed miRNA, let 7-a is a direct target of EWS-FLI1 & {$[51]$} \\
\hline miRNA 17-92 cluster & EWS-FLI1 induced miRNAs & {$[51]$} \\
\hline
\end{tabular}

and in vivo via interaction with the EWS amino terminal domain [86]. In addition, experimental evidence for a direct interaction between EWS-FLI1 and EWS was reported by Spahn et al. [20]. Since EWS interacts with a multitude of RNA processing factors [21], the functional consequences of this heterodimerization on RNA splicing remains a subject for further investigation (summarized in Table 1).

\section{Factors Indirectly Affecting EWS-FLI1 Activity}

4.1. $p 53$ and INK4A Pathways. The p53 and INK4A (p16/p14ARF) pathways are critical in promoting cell cycle arrest in response to mitogenic signals, and mutations in their key components facilitate tumor progression in most cancer types $[89,90]$. In normal primary mouse fibroblasts (MEFs), EWS-FLI1 expression is unstable eliciting a p53dependent growth arrest and apoptosis program. However, in p16 or p53 defective MEFs, these effects are attenuated and this environment allows stable expression of the fusion protein $[27,28]$. Thus, it appears that the loss of each of these tumor suppressor genes stabilizes EWS-FLI1 expression.
Consistent with this finding, loss of p53 greatly accelerates tumorigenesis in EWS-FLI1 transgenic mice [29]. However, in ESFT, mutations in $p 53$ or $p 16 / p 14 A R F$ are found in approximately $10 \%$ and $25 \%$ of cases, respectively. As in most pediatric malignancies, the majority of ESFT express wild-type $p 53$ and $p 16 / 14 A R F$ genes [30-32]. Functionally, basal p53 expression is modulated by EWS-FLI1 through an indirect mechanism that involves suppression of the Notch signalling pathway [33].

4.2. Hypoxia. Hypoxia is a common condition in solid tumors. It drives cancer cells towards a coordinated set of survival responses altering the transcriptional regulation of many genes [91], stimulating cell migration, invasiveness and motility [92], and driving a metabolic shift towards anaerobic glycolysis [93] or promotion of autophagy [94]. Due to its involvement in drug resistance [95], hypoxia has been identified as a negative prognostic factor in many cancers [96] including sarcomas [97]. HIF-1, a basic HLH transcription factor, is a major player in the adaptive response to hypoxic conditions, enhancing cell survival in this unfavourable environment [92-98]. In ESFT, hypoxia has been shown to contribute to apoptosis resistance via 
HIF- $1 \alpha$ [99], to chemotherapy resistance [34], and to the establishment of an alternative circulatory system [35]. Interestingly, under hypoxic conditions, EWS-FLI1 protein expression was demonstrated to increase transiently in a HIF-1 $\alpha$-dependent manner [36]. HIF- $1 \alpha$-mediated EWS-FLI1 accumulation involved protein regulation at the FLI1 moiety, since the observed protein accumulation was restricted to EWS-FLI1 and neither observed for full-length EWS nor for an alternative EWS fusion to ERG. On the transcriptional level, however, the upregulation of EWS-FLI1 protein did not simply result in a reinforcement of the EWSFLI1 transcriptional signature, but showed a more complex effect with both synergistic and antagonistic consequences on EWS-FLI1 regulated genes [36]. Another study has shown colocalisation of HIF- $1 \alpha$ and necrotic areas in an ESFT tissue array, suggesting a role for hypoxia in in vivo induction of HIF-1 $\alpha$ [37]. Data thus implicates HIF as the main response factor for hypoxic stimulus in ESFT with marked effects on proliferation and apoptosis.

4.3. IGF-1/IGF-1R and bFGF Pathways. The autocrine loops encompassing (IGF-1)/(IGF-1R) and (IGF-2)/(IGF-2R) play a crucial role in the proliferation and survival of ESFT cells via activation of AKT and ERK1/2 [38-40]. Notably, in MEFs, expression of IGF-1R is required for EWSFLI1-mediated cellular transformation suggesting that the oncogenic activity of the fusion protein is dependent on functional IGF-1R signaling [41]. There are several lines of evidence that support a link between EWS-FLI1 and IGF1/IGF1-R signalling $[42,43]$ also in one of the putative progenitor cell of ESFT [44], and inhibition of this signaling pathway reduces tumor growth in vitro [45] and in vivo [54], blocks angiogenesis [55], induces cell death [61], and increases chemosensitivity [100].

A further growth factor positively interacting with EWSFLI1 activity is basic fibroblast growth factor (bFGF). bFGF was demonstrated to trigger EWS-FLI1 expression in serumdepleted ESFT cells. A neutralizing antibody against bFGF was able to disrupt this upregulation and inhibit expression of the fusion protein in a broad panel of ESFT cell lines [46]. No detectable effect on EWS-FLI1 expression levels was observed upon epidermal growth factor or platelet derived growth factor stimulation. However, the mechanism by which bFGF specifically controls EWS-FLI1 levels remains elusive

Most recently, a further putative signalling molecule that is expressed on the cell surface, the bladder cancer associated protein BLCAP, carrying a putative Ser-Pro-X-X motif and a proline-rich area, was reported to modulate EWS-FLI1 expression [47]. The mechanism of this activity, which was obtained upon artificial ectopic overexpression, remains to be elucidated (summarized in Table 1).

\section{5. miRNAs Influencing EWS-FLI1 Activity}

MicroRNAs (miRNAs) are small (21-24 nucleotides), singlestranded, and noncoding RNAs that regulate gene expression in a variety of cellular processes [101]. By binding of the
miRNA to a partially homologous region (seed region) within the $3^{\prime}$ untranslated region (UTR), coding sequences or $5^{\prime}$ UTRs of messenger RNAs (mRNA), it can either block its target mRNA translation or lead to its degradation [102, 103]. Due to the imperfect base pairing of the miRNA to its seed region, a single miRNA can regulate several target mRNAs as part of a complex gene regulatory network [101, 104]. It is estimated that between $30 \%$ and $60 \%$ of the human genome is regulated by miRNAs including genes involved in mechanisms of tumorigenesis, such as proliferation, inflammation, stress response, apoptosis, differentiation, and invasion [101, 102]. miRNAs can either act as oncogenes or tumor suppressors, some of them even in both ways $[101,105,106]$.

While the role of aberrantly expressed miRNAs is well established in adult cancers, only few studies exist for pediatric malignancies in general and sarcomas in particular [107-109]. One of the best described tumor suppressive miRNAs is miR-145, which was found to be downregulated in several solid tumors, including lung, colorectal, breast, and prostate cancer $[110,111]$. Similarly, in ESFT, miR145 was recently described as the top consistently EWS-FLI1 repressed miRNA. This finding was based on the investigation of five ESFT cell lines upon RNA interference-mediated EWS-FLI1 knockdown and on differential gene expression patterns between primary ESFT and mesenchymal stem cells, the most related normal tissue. In fact, miR-145 and EWS-FLI1 were demonstrated to build a regulatory feedback loop, in which EWS-FLI1 suppresses miR-145 and miR145 modulates EWS-FLI1 expression [48, 49]. This type of positive feedback regulation has the potential to serve as a compensating buffer for variations in EWS-FLI1 expression. Reconstitution of miR-145 expression resulted in decreased EWS-FLI1 expression and consequently reduced cell growth and soft agar colony formation [48]. Of note, miR-145 has recently been reported to target the 3'UTR of another ETS family gene, ERG, which replaces FLI in alternative EWS fusions associated with about 10\% of ESFT [112]. The DNA binding domain of ERG shares $98 \%$ homology with that of FLI1 [113] and our own unpublished results suggest that there is significant overlap between EWS-FLI1 target genes in ESFT and ERG in prostate cancer cells. Although activity of miR-145 on EWS-ERG in ESFT remains to be demonstrated, the finding of ERG modulation by this miRNA in prostate cancer cells may extend the concept of feedback regulation between EWS-ETS fusion genes and miR-145 beyond EWSFLI1.

However, a recent global miRNA profiling study in the A673 ESFT cell line did not confirm miR-145 among EWSFLI1 suppressed miRNAs but described a group of EWSFLI1 repressed miRNAs (miR-100, miR-125b, miR-22, miR221/222, miR-271, and miR29a) with predicted targets in the IGF-1/IGF-1R signaling pathway [50], a key growth regulatory signaling pathway interacting with EWS-FLI1 expression/activity [41-43]. The lack of evidence for miR145 suppression in this study [50] as compared to the previous study [48] may be caused by the use of different cell lines, different screening platforms (Agilent-type microarray versus Applied Biosystems quantitative stem loop 
PCR), and/or the different timing of miRNA screening after EWS-FLI1 knockdown (10 days in [50] versus 4 days in [48]). miR-145 is the first miRNA shown to target FLI1 and FLI1 fusion genes $[48,49,110]$. Given the length of the FLI1 $3^{\prime}$ UTR $(>2 \mathrm{~kb})$, it is very likely that other miRNAs may have similar FLI1 and EWS-FLI1 modulatory activities (summarized in Table 1).

\section{Therapeutic Potentials}

The existence of tumor-specific alterations in several cancers presents a unique opportunity for pharmacological intervention to therapeutic benefit. Although EWS-FLI1 has only been identified in tumor cells and therefore provides a potential ideal therapeutic target, ESFT has so far remained a targetable disease without a targeted drug $[71,114]$. Suppression of EWS-FLI1 has been achieved by antisense technologies [115-121], small interfering RNA (siRNA) [122-125], short hairpin RNA (shRNA) [42, 126128], and small pharmacological compounds [53, 62] all blocking the proliferation of ESFT cell lines and xenografted tumors. Although some siRNA coupled to nanoparticles have proved to be useful in preclinical models either alone [129-132] or combined with other therapeutic agents as rapamycin [133], the general lack of clinical translation of some of these macromolecule-based strategies lies in the challenge of pharmacological delivery [134]. Being present only in tumor cells, directly targeting the activity of EWSFLI1 by focusing on its protein-protein interactions, will be a logical step towards identifying potential targets for developing effective anti-ESFT therapies. Along this line, targeting binding partners essential for EWS-FLIl oncogenic function holds promise in combating ESFT as has been shown for RNA helicase A using the small molecule YK-4279 [53]. YK-4-279 blocked RNA helicase A binding to EWSFLI1, induced apoptosis in ESFT cell lines and also reduced growth in ESFT xenografts. YK-4-279 can also target a subpopulation of chemoresistant ESFT stem cells [135] and it has been recently described as an effective antiinvasive agent in ETV1 and ERG fusion positive prostate tumors although the mechanism of action of YK-4-279 in prostate cancer cells seems to be different [136]. A further evaluation of this new role of YK-4-279 in ESFT would be needed. O-linked beta$\mathrm{N}$-acetylglucosamine (O-GlcNAc), which modifies nuclear and cytoplasmic proteins on serine and threonine residues, was delineated to serine/threonine residues of the aminoterminal EWS transcriptional-activation domain of the EWS-FLI1 fusion protein by our laboratory. Inhibition of EWS-FLI1 O-GlcNAcylation interfered with transactivation of its target gene $I d 2$ [12]. A better understanding of EWSFLI1 O-GlcNAcylation as it relates to gene transcription and the physiological mechanisms behind this process is likely to lead to novel therapies for treating ESFT. Recently, our group identified a positive feedback regulation between EWS-FLI1 and miR-145 as an important component of EWS-FLI1 mediated tumorigenesis [48]. As such, targeting miR-145 or other miRNAs found to affect EWS-FLI1 activity may serve as a promising therapy strategy to improve the clinical outcome of ESFT patients. Also, the adaptation of tumors to hypoxia is critical for their survival and growth. Given the central role hypoxia plays in tumor progression and resistance to therapy, hypoxia might well be considered the best validated target that has yet to be exploited in oncology [137]. Some established drugs targeting hypoxia or the HIF1 pathway (e.g., 2-methoxyestradiol, bortezomib) have been already tested in ESFT [63-65] and although bortezomib per se showed no clinical benefit [138] and resistance appeared, [139] the recent finding of hypoxia transiently enhancing EWS-FLI1 protein expression [36] may raise hopes for a combined therapeutic window for ESFT patients with new agents. Also, therapeutic strategies targeting the IGF1/IGF-1R loop may interfere with oncogenic functions of EWS-FLI1. Antagonistic IGF-1R antibodies or small kinase inhibitory molecules have been developed and are therefore currently tested in phase I/II clinical trials on ESFT patients either alone [56-58] or in combination with the mTOR inhibitor temsirolimus [59] showing promising results. One important fact is the status of the insulin receptor (IR) as ESFT patients with a low IGF-1R:IR ratio do not benefit from anti-IGF-1R therapies [60]. A meta-analysis of smallscale retrospective studies suggest that, although rare, ESFT harbouring $p 53$ or $p 16 / p 14 A R F$ mutations form a subset with particularly poor prognosis, highly aggressive behaviour, and poor chemoresponse [140, 141]. Nutlin-3a, a small molecule which antagonizes the interaction of MDM2 with p53, thus stabilizing the tumor suppressor protein, is able to promote a strong apoptotic arrest when applied to ESFT and showed a synergistic effect with other chemotherapeutic agents such as etoposide, doxorubicin, vincristine, and actinomycin $\mathrm{D}$ in a dose-dependent manner [66, 67]. As downstream targets of EWS-FLI1 have been reported to contribute to the oncogenic activities of EWS-FLI1 [19, 25, 85, 126, 142-145], generating compounds effectively targeting these downstream effectors hold potential therapeutic benefits as has been shown with ET-743 [68], Mithramycin [62], and ARA-C [69] although it is necessary to be cautious as, for example, ARA-C has shown minimal activity and hematologic toxicity in a phase II clinical trial [70]. Methods to evaluate the specificity, toxicity, metabolism, and excretion as well as adsorption and distribution within tumor cells are warranted to advance these potential drugs into clinical trials (summarized in Table 2).

\section{Conclusion}

While attempts to understand the pathobiology of ESFT have focused mainly on identifying EWS-FLI1 target genes and downstream pathways, there are still many important unresolved questions regarding factors modulating EWSFLI1 activity. Manipulation of these factors may offer therapeutic promise since it is difficult to directly target a transcription factor. This may be achieved by applying high throughput compound screening technologies as has been performed to block EWS-FLI1 interaction with RNA helicase A $[22,53]$, and in EWS-FLI1 signature-based approaches as in the case of Mithramycin [62]. Such compounds may be 
TABLE 2: Therapeutic agents targeting partners essential for EWS-FLI1.

\begin{tabular}{|c|c|c|c|}
\hline Name & Characteristics & Effects & Reference \\
\hline Mevalonate, tunicamycin & Inhibitors of N-linked glycosylation & $\begin{array}{l}\text { EWS-FLI1 expression, growth arrest, inactivation } \\
\text { of IGF-1R signaling }\end{array}$ & {$[12-14]$} \\
\hline Lovastatin & HMG-CoA reductase inhibitor & $\begin{array}{l}\text { Triggering of differentiation, induction of } \\
\text { apoptosis, inactivation of IGF-1R signaling }\end{array}$ & {$[14,52]$} \\
\hline YK-4-279 & $\begin{array}{l}\text { Blocking RNA helicase A binding to } \\
\text { EWS-FLI1 }\end{array}$ & $\begin{array}{l}\text { Induction of apoptosis in vitro and reduction of } \\
\text { growth in vivo }\end{array}$ & {$[53]$} \\
\hline Anti-IGF-1R antibodies & Blocking IGF-1/IGF-1R pathway & $\begin{array}{l}\text { Tumor growth reduction in vitro and in vivo, } \\
\text { angiogenesis blockage, cell death induction and } \\
\text { chemosensitivity increase }\end{array}$ & $\begin{array}{l}{[45,54-} \\
60]\end{array}$ \\
\hline Epigallocatechin gallate & IGF-1R inhibitor, catechin derivative & Blocks proliferation and induces cell death & {$[61]$} \\
\hline $\begin{array}{l}\text { Neutralizing antibody } \\
\text { against bFGF }\end{array}$ & Blocking bFGF pathway & $\begin{array}{l}\text { EWS-FLI1 downregulation through inhibition of } \\
\text { FGFR phosphorylation }\end{array}$ & {$[46]$} \\
\hline Mithramycin & DNA binding transcriptional inhibitor & $\begin{array}{l}\text { EWS-FLI1 inhibitor, decreases tumor growth in } \\
\text { vitro and in vivo }\end{array}$ & {$[62]$} \\
\hline $\begin{array}{l}\text { 2-methoxyestradiol, } \\
\text { bortezomib }\end{array}$ & Inhibitors of hypoxia and/or HIF-1 pathway & $\begin{array}{l}\text { Induction of apoptosis, autophagy and cell cycle } \\
\text { arrest in vitro }\end{array}$ & {$[63-65]$} \\
\hline Nutlin-3a & $\begin{array}{l}\text { Small molecule which antagonizes the } \\
\text { interaction of MDM2 with p53 }\end{array}$ & $\begin{array}{l}\text { Stabilization of p53, apoptotic arrest, synergistic } \\
\text { effect with other chemotherapeutic agents }\end{array}$ & {$[66,67]$} \\
\hline Ecteinascidin 743 & $\begin{array}{l}\text { Binds and alkylates DNA at the N2 position } \\
\text { of guanine }\end{array}$ & $\begin{array}{l}\text { Induction of apoptosis, reduction of the activity } \\
\text { of EWS-FLI1 targets }\end{array}$ & {$[68]$} \\
\hline $\begin{array}{l}\text { ARA-C (cytosine } \\
\text { arabinoside) }\end{array}$ & Antimetabolite, inhibitor of EWS-FLI1 & $\begin{array}{l}\text { EWS-FLI1 protein reduction, decrease of cell } \\
\text { viability, transformation and tumor growth in } \\
\text { vivo }\end{array}$ & {$[69,70]$} \\
\hline Synthetic Let-7a & Synthetic miRNA & $\begin{array}{l}\text { Restored Let-7a expression resulted in ESFT } \\
\text { growth inhibition in vivo }\end{array}$ & {$[51]$} \\
\hline
\end{tabular}

more specific and highly effective in neutralising EWS-FLI1 activity in ESFT cells with minimal toxicity.

The list of agents influencing EWS-FLI1 fusion protein activity and/or expression is consistently enriched. Some of them show crosstalk, as has been demonstrated between a group of EWS-FLI1 repressed miRNAs and targets of IGF$1 /$ IGF-1R pathway [50]. Since very little is known about the influence of miRNAs on EWS-FLI1 activity, employing high-throughput screening assays to identify miRNAs with specific effects on EWS-FLI1 activity will provide additional targets for therapeutic development. Recently, the use of miRNA arrays to compare the miRNA expression profile of human mesenchymal stem cells (MSCs) and ESFT cell lines has shown induction of the oncogenic miRNA 17-92 cluster and repression of the tumor suppressor let-7 family. Importantly, the feasibility of delivery of synthetic miRNA in vivo to achieve tumor growth inhibition was demonstrated in this study [51]. For a better understanding of the interplay between the discussed factors, it should be crucial to also consider the individual clinical profiles of ESFT patients.

\section{Abbreviations}

ESFT: Ewing's sarcoma family tumors

EAD: EWS activation domain

DBD: DNA-binding domain

SH2: Src Homology 2

O-GlcNAcylation: O-linked

HMG-CoA:

RB:

IGF-1:

IGF-1R:

CBP:

RHA:

MMP-1:

BARD1:

snRNP:

MEFs:

HIF-1:

bFGF:

IGF-2:

IGF-2R:

miRNA:

UTR:

mRNA:

shRNA:

O-GlcNAc:

ARA-C:

IR:

MSCs:

BLCAP: beta- $\mathrm{N}$-acetylglucosaminylation 3-Hydroxy-3-methylglutaryl-coenzyme A

Retinoblastoma

Insulin-like growth factor 1 Insulin-like growth factor receptor 1 Creb-binding protein RNA helicase A

Matrix metalloproteinase BRCA1-associated RING domain protein 1 Small nuclear ribonucleoprotein Mouse embryonic fibroblasts Hypoxia-inducible factor-1 Basic fibroblast growth factor Insulin-like growth factor 2 Insulin-like growth factor receptor 2 MicroRNA $3^{\prime}$ untranslated region Messenger RNA Short hairpin RNA $\mathrm{O}$-linked beta-N-acetylglucosamine Cytosine arabinoside Insulin receptor Human mesenchymal stem cells Bladder cancer-associated protein. 


\section{Acknowledgments}

The authors would like to thank Dr. Heinrich Kovar for constructive discussions and critical comments. All authors have contributed equally to the paper.

\section{References}

[1] O. Delattre, J. Zucman, B. Plougastel et al., "Gene fusion with an ETS DNA-binding domain caused by chromosome translocation in human tumours," Nature, vol. 359, no. 6391, pp. 162-165, 1992.

[2] H. Kovar, "Downstream EWS/FLI1-upstream Ewing's sarcoma," Genome Medicine, vol. 2, no. 1, article 8, 2010.

[3] C. Mackintosh, J. Madoz-Gúrpide, J. L. Ordóñez, D. Osuna, and D. Herrero-Martín, "The molecular pathogenesis of Ewing's sarcoma," Cancer Biology and Therapy, vol. 9, no. 9, pp. 653-665, 2010.

[4] N. Riggi, M. L. Suvà, D. Suvà et al., "EWS-FLI-1 expression triggers a ewing's sarcoma initiation program in primary human mesenchymal stem cells," Cancer Research, vol. 68, no. 7, pp. 2176-2185, 2008.

[5] N. Riggi, M.-L. Suvà, and I. Stamenkovic, "The cancer stem cell paradigm in Ewing's sarcoma: what can we learn about these rare cells from a rare tumor?" Expert Review of Anticancer Therapy, vol. 11, no. 2, pp. 143-145, 2011.

[6] C. von Levetzow, X. Jiang, Y. Gwye et al., "Modeling initiation of ewing sarcoma in human neural crest cells," PLoS One, vol. 6, no. 4, Article ID e19305, 2011.

[7] J. D. Hancock and S. L. Lessnick, "A transcriptional profiling meta-analysis reveals a core EWS-FLI gene expression signature," Cell Cycle, vol. 7, no. 2, pp. 250-256, 2008.

[8] M. Kauer, J. Ban, R. Kofler et al., "A molecular function map of Ewing's sarcoma," PLoS One, vol. 4, no. 4, Article ID e5415, 2009.

[9] R. J. Olsen and S. H. Hinrichs, "Phosphorylation of the EWS IQ domain regulates transcriptional activity of the EWS/ATF1 and EWS/FLI1 fusion proteins," Oncogene, vol. 20, no. 14, pp. 1756-1764, 2001.

[10] J. C. Deloulme, L. Prichard, O. Delattre, and D. R. Storm, "The prooncoprotein EWS binds calmodulin and is phosphorylated by protein kinase $\mathrm{C}$ through an IQ domain," The Journal of Biological Chemistry, vol. 272, no. 43, pp. 2736927377, 1997.

[11] I. V. Klevernic, S. Morton, R. J. Davis, and P. Cohen, "Phosphorylation of Ewing's sarcoma protein (EWS) and EWS-Fli1 in response to DNA damage," Biochemical Journal, vol. 418, no. 3, pp. 625-634, 2009.

[12] R. Bachmaier, D. N. T. Aryee, G. Jug et al., "O-GlcNAcylation is involved in the transcriptional activity of EWS-FLI1 in Ewing's sarcoma," Oncogene, vol. 28, no. 9, pp. 1280-1284, 2009.

[13] M. Wang, Y. Xie, L. Girnita et al., "Regulatory role of mevalonate and $\mathrm{N}$-linked glycosylation in proliferation and expression of the EWS/FLI-1 fusion protein in Ewing's sarcoma cells," Experimental Cell Research, vol. 246, no. 1, pp. 38-46, 1999.

[14] L. Girnita, M. Wang, Y. Xie et al., "Inhibition of N-linked glycosylation down-regulates insulin-like growth factor-1 receptor at the cell surface and kills Ewing's sarcoma cells: therapeutic implications," Anti-Cancer Drug Design, vol. 15, no. 1, pp. 67-72, 2000.
[15] L. Yang, H. A. Chansky, and D. D. Hickstein, "EWS· Fli1 fusion protein interacts with hyperphosphorylated RNA polymerase II and interferes with serine-arginine proteinmediated RNA splicing," The Journal of Biological Chemistry, vol. 275, no. 48, pp. 37612-37618, 2000.

[16] R. Petermann, B. M. Mossier, D. N. T. Aryee, V. Khazak, E. A. Golemis, and H. Kovar, "Oncogenic EWS-Flil interacts with hsRPB7, a subunit of human RNA polymerase II," Oncogene, vol. 17, no. 5, pp. 603-610, 1998.

[17] R. Todorova, "In vitro interaction between the N-terminus of the Ewing's sarcoma protein and the subunit of RNA polymerase II hsRPB7," Molecular Biology Reports, vol. 36, no. 6, pp. 1269-1274, 2009.

[18] H. Zhou and K. A. W. Lee, "An hsRPB4/7-dependent yeast assay for trans-activation by the EWS oncogene," Oncogene, vol. 20, no. 12, pp. 1519-1524, 2001.

[19] R. Ramakrishnan, Y. Fujimura, J. P. Zou et al., "Role of protein-protein interactions in the antiapoptotic function of EWS-Fli-1," Oncogene, vol. 23, no. 42, pp. 7087-7094, 2004.

[20] L. Spahn, C. Siligan, R. Bachmaier, J. A. Schmid, D. N. T. Aryee, and H. Kovar, "Homotypic and heterotypic interactions of EWS, FLI1 and their oncogenic fusion protein," Oncogene, vol. 22, no. 44, pp. 6819-6829, 2003.

[21] S. Pahlich, L. Quero, B. Roschitzki, R. P. Leemann-Zakaryan, and H. Gehring, "Analysis of Ewing sarcoma (EWS)-binding proteins: interaction with hnRNP M, U, and RNA-helicases p68/72 within protein-RNA complexes," Journal of Proteome Research, vol. 8, no. 10, pp. 4455-4465, 2009.

[22] J. A. Toretsky, V. Erkizan, A. Levenson et al., "Oncoprotein EWS-FLI1 activity is enhanced by RNA helicase A," Cancer Research, vol. 66, no. 11, pp. 5574-5581, 2006.

[23] L. Spahn, R. Petermann, C. Siligan, J. A. Schmid, D. N. T. Aryee, and H. Kovar, "Interaction of the EWS NH2 terminus with BARD1 links the Ewing's sarcoma gene to a common tumor suppressor pathway," Cancer Research, vol. 62, no. 16, pp. 4583-4587, 2002.

[24] S. Kim, C. T. Denny, and R. Wisdom, "Cooperative DNA binding with AP-1 proteins is required for transformation by EWS-Ets fusion proteins," Molecular and Cellular Biology, vol. 26, no. 7, pp. 2467-2478, 2006.

[25] M. Kinsey, R. Smith, A. K. Iyer, E. R. B. McCabe, and S. L. Lessnick, "EWS/FLI and its downstream target NR0B1 interact directly to modulate transcription and oncogenesis in Ewing's sarcoma," Cancer Research, vol. 69, no. 23, pp. 9047-9055, 2009.

[26] L. L. Knoop and S. J. Baker, "EWS/FLI alters 5'-splice site selection," The Journal of Biological Chemistry, vol. 276, no. 25, pp. 22317-22322, 2001.

[27] B. Deneen and C. T. Denny, "Loss of p16 pathways stabilizes EWS/FLI1 expression and complements EWS/FLI1 mediated transformation," Oncogene, vol. 20, no. 46, pp. 6731-6741, 2001.

[28] S. L. Lessnick, C. S. Dacwag, and T. R. Golub, "The Ewing's sarcoma oncoprotein EWS/FLI induces a p53-dependent growth arrest in primary human fibroblasts," Cancer Cell, vol. 1, no. 4, pp. 393-401, 2002.

[29] P. P. Lin, M. K. Pandey, F. Jin et al., "EWS-FLI1 induces developmental abnormalities and accelerates sarcoma formation in a transgenic mouse model," Cancer Research, vol. 68, no. 21, pp. 8968-8975, 2008.

[30] H. Kovar, G. Jug, D. N. T. Aryee et al., "Among genes involved in the RB dependent cell cycle regulatory cascade, the p16 tumor suppressor gene is frequently lost in the Ewing family of tumors," Oncogene, vol. 15, no. 18, pp. 2225-2232, 1997. 
[31] J. A. López-Guerrero, A. Pellín, R. Noguera, C. Carda, and A. Llombart-Bosch, "Molecular analysis of the 9p21 locus and p53 genes in Ewing family tumors," Laboratory Investigation, vol. 81, no. 6, pp. 803-814, 2001.

[32] E. De Alava, C. R. Antonescu, A. Panizo et al., "Prognostic impact of P53 status in Ewing sarcoma," Cancer, vol. 89, no. 4, pp. 783-792, 2000.

[33] J. Ban, I. M. Bennani-Baiti, M. Kauer et al., "EWS-FLI1 suppresses NOTCH-activated p53 in Ewing's sarcoma," Cancer Research, vol. 68, no. 17, pp. 7100-7109, 2008.

[34] S. Batra, C. P. Reynolds, and B. J. Maurer, "Fenretinide cytotoxicity for Ewing's sarcoma and primitive neuroectodermal tumor cell lines is decreased by hypoxia and synergistically enhanced by ceramide modulators," Cancer Research, vol. 64, no. 15 , pp. 5415-5424, 2004.

[35] D. W. J. Van Der Schaft, F. Hillen, P. Pauwels et al., “Tumor cell plasticity in Ewing sarcoma, an alternative circulatory system stimulated by hypoxia," Cancer Research, vol. 65, no. 24, pp. 11520-11528, 2005.

[36] D. N. T. Aryee, S. Niedan, M. Kauer et al., "Hypoxia modulates EWS-FLI1 transcriptional signature and enhances the malignant properties of Ewing's Sarcoma cells In vitro," Cancer Research, vol. 70, no. 10, pp. 4015-4023, 2010.

[37] H. J. Knowles, K. L. Schaefer, U. Dirksen, and N. A. Athanasou, "Hypoxia and hypoglycaemia in Ewing's sarcoma and osteosarcoma: regulation and phenotypic effects of Hypoxia-Inducible Factor," BMC Cancer, vol. 10, article 372, 2010.

[38] D. Yee, R. E. Favoni, G. S. Lebovic et al., "Insulin-like growth factor I expression by tumors of neuroectodermal origin with the $\mathrm{t}(11 ; 22)$ chromosomal translocation. A potential autocrine growth factor," The Journal of Clinical Investigation, vol. 86, no. 6, pp. 1806-1814, 1990.

[39] K. Scotlandi, M. C. Manara, M. Serra et al., "Expression of insulin-like growth factor system components in Ewing's sarcoma and their association with survival," European Journal of Cancer, vol. 47, no. 8, pp. 1258-1266, 2011.

[40] S. E. Steigen, D. F. Schaeffer, R. B. West, and T. O. Nielsen, "Expression of insulin-like growth factor 2 in mesenchymal neoplasms," Modern Pathology, vol. 22, no. 7, pp. 914-921, 2009.

[41] J. A. Toretsky, T. Kalebic, V. Blakesley, D. LeRoith, and L. J. Helman, "The insulin-like growth factor-I receptor is required for EWS/FLI-1 transformation of fibroblasts," The Journal of Biological Chemistry, vol. 272, no. 49, pp. 3082230827, 1997.

[42] D. Herrero-Martín, D. Osuna, J. L. Ordó ez et al., "Stable interference of EWS-FLI1 in an Ewing sarcoma cell line impairs IGF-1/IGF-1R signalling and reveals TOPK as a new target," British Journal of Cancer, vol. 101, no. 1, pp. 80-90, 2009.

[43] T. Baumuratova, D. Surdez, B. Delyon et al., "Localizing potentially active post-transcriptional regulations in the Ewing's sarcoma gene regulatory network," BMC Systems Biology, vol. 4, article 146, 2010.

[44] L. Cironi, N. Riggi, P. Provero et al., "IGF1 is a common target gene of Ewing's sarcoma fusion proteins in mesenchymal progenitor cells," PLoS One, vol. 3, no. 7, Article ID e2634, 2008.

[45] K. Scotlandi, S. Benini, M. Sarti et al., "Insulin-like growth factor I receptor-mediated circuit in Ewing's sarcoma/peripheral neuroectodermal tumor: a possible therapeutic target," Cancer Research, vol. 56, no. 20, pp. 4570 4574, 1996.
[46] L. Girnita, A. Girnita, M. Wang, J. M. Meis-Kindblom, L. G. Kindblom, and O. Larsson, "A link between basic fibroblast growth factor (bFGF) and EWS/FLI-1 in Ewing's sarcoma cells," Oncogene, vol. 19, no. 37, pp. 4298-4301, 2000.

[47] D. G. Fan, F. Zhao, Y. Ding et al., "BLCAP induces apoptosis in human Ewing's sarcoma cells," Experimental Biology and Medicine, vol. 236, no. 9, pp. 1030-1035, 2011.

[48] J. Ban, G. Jug, P. Mestdagh et al., "Hsa-mir-145 is the top EWS-FLI1-repressed microRNA involved in a positive feedback loop in Ewing's sarcoma," Oncogene, vol. 30, no. 18, pp. 2173-2180, 2011.

[49] N. Riggi, M. L. Suvà, C. De Vito et al., "EWS-FLI-1 modulates miRNA145 and SOX2 expression to initiate mesenchymal stem cell reprogramming toward Ewing sarcoma cancer stem cells," Genes and Development, vol. 24, no. 9, pp. 916-932, 2010.

[50] E. L. McKinsey, J. K. Parrish, A. E. Irwin et al., "A novel oncogenic mechanism in Ewing sarcoma involving IGF pathway targeting by EWS/Flil-regulated microRNAs," Oncogene. In press.

[51] C. De Vito, N. Riggi, M.-L. Suvà et al., "Let-7a is a direct EWS-FLI-1 target implicated in Ewing's sarcoma development," PLoS One, vol. 6, no. 8, Article ID e23592, 2011.

[52] J. S. Kim, F. Pirnia, Y. H. Choi et al., "Lovastatin induces apoptosis in a primitive neuroectodermal tumor cell line in association with RB down-regulation and loss of the G1 checkpoint," Oncogene, vol. 19, no. 52, pp. 6082-6090, 2000.

[53] H. V. Erkizan, Y. Kong, M. Merchant et al., "A small molecule blocking oncogenic protein EWS-FLI1 interaction with RNA helicase A inhibits growth of Ewing's sarcoma," Nature Medicine, vol. 15, no. 7, pp. 750-756, 2009.

[54] K. Scotlandi, S. Benini, P. Nanni et al., "Blockage of insulinlike growth factor-I receptor inhibits the growth of Ewing's sarcoma in athymic mice," Cancer Research, vol. 58, no. 18, pp. 4127-4131, 1998.

[55] R. Strammiello, S. Benini, M. C. Manara et al., "Impact of IGF-I/IGF-IR circuit on the angiogenetic properties of Ewing's sarcoma cells," Hormone and Metabolic Research, vol. 35, no. 11-12, pp. 675-684, 2003.

[56] D. Olmos, S. Postel-Vinay, L. R. Molife et al., "Safety, pharmacokinetics, and preliminary activity of the anti-IGF1R antibody figitumumab (CP-751,871) in patients with sarcoma and Ewing's sarcoma: a phase 1 expansion cohort study," The Lancet Oncology, vol. 11, no. 2, pp. 129-135, 2010.

[57] J. A. Toretsky and R. Gorlick, "IGF-1R targeted treatment of sarcoma," The Lancet Oncology, vol. 11, no. 2, pp. 105-106, 2010.

[58] R. Kurzrock, A. Patnaik, J. Aisner et al., "A phase I study of weekly R1507, a human monoclonal antibody insulinlike growth factor-I receptor antagonist, in patients with advanced solid tumors," Clinical Cancer Research, vol. 16, no. 8, pp. 2458-2465, 2010.

[59] A. Naing, R. Kurzrock, A. M. Burger et al., "Phase I trial of cixutumumab combined with temsirolimus in patients with advanced cancer," Clinical Cancer Research, vol. 17, no. 18, pp. 6052-6060, 2011.

[60] C. Garofalo, M. C. Manara, G. Nicoletti et al., "Efficacy of and resistance to anti-IGF-1R therapies in Ewing's sarcoma is dependent on insulin receptor signaling," Oncogene, vol. 30, no. 24, pp. 2730-2740, 2011.

[61] H. G. Kang, J. M. Jenabi, X. F. Liu, C. P. Reynolds, T. J. Triche, and P. H. B. Sorensen, "Inhibition of the insulin-like growth factor I receptor by epigallocatechin gallate blocks proliferation and induces the death of ewing tumor cells," 
Molecular Cancer Therapeutics, vol. 9, no. 5, pp. 1396-1407, 2010.

[62] P. J. Grohar, G. M. Woldemichael, L. B. Griffin et al., "Identification of an inhibitor of the EWS-FLI1 oncogenic transcription factor by high-throughput screening," Journal of the National Cancer Institute, vol. 103, no. 12, pp. 962-978, 2011.

[63] M. Djavaheri-Mergny, J. Wietzerbin, and F. Besançon, “2Methoxyestradiol induces apoptosis in Ewing sarcoma cells through mitochondrial hydrogen peroxide production," Oncogene, vol. 22, no. 17, pp. 2558-2567, 2003.

[64] S. Lorin, A. Borges, L. R. Dos Santos et al., "c-Jun NH2terminal kinase activation is essential for DRAM-dependent induction of autophagyand apoptosis in 2-methoxyestradioltreated ewing sarcoma cells," Cancer Research, vol. 69, no. 17, pp. 6924-6931, 2009.

[65] G. Lu, V. Punj, and P. M. Chaudhary, "Proteasome inhibitor Bortezomib induces cell cycle arrest and apoptosis in cell lines derived from Ewing's sarcoma family of tumors and synergizes with TRAIL," Cancer Biology and Therapy, vol. 7, no. 4, pp. 603-608, 2008.

[66] K. I. Pishas, F. Al-Ejeh, I. Zinonos et al., "Nutlin-3a is a potential therapeutic for Ewing sarcoma," Clinical Cancer Research, vol. 17, no. 3, pp. 494-504, 2011.

[67] J. Sonnemann, C. D. Palani, S. Wittig et al., "Anticancer effects of the p53 activator nutlin-3 in Ewing's sarcoma cells," European Journal of Cancer, vol. 47, no. 9, pp. 1432-1441, 2011.

[68] P. J. Grohar, L. B. Griffin, C. Yeung et al., "Ecteinascidin 743 interferes with the activity of EWS-FLI1 in ewing sarcoma cells," Neoplasia, vol. 13, no. 2, pp. 145-153, 2011.

[69] K. Stegmaier, J. S. Wong, K. N. Ross et al., "Signature-based small molecule screening identifies cytosine arabinoside as an EWS/FLI modulator in ewing sarcoma," PLoS Medicine, vol. 4, no. 4, article e122, 2007

[70] S. G. Dubois, M. D. Krailo, S. L. Lessnick et al., "Phase II study of intermediate-dose cytarabine in patients with relapsed or refractory ewing sarcoma: a report from the children's oncology group," Pediatric Blood and Cancer, vol. 52, no. 3, pp. 324-327, 2009.

[71] A. Uren and J. A. Toretsky, "Ewing's sarcoma oncoprotein EWS-FLI1: the perfect target without a therapeutic agent," Future Oncology, vol. 1, no. 4, pp. 521-528, 2005.

[72] K. P. Ng, G. Potikyan, R. O. V. Savene, C. T. Denny, V. N. Uversky, and K. A. W. Lee, "Multiple aromatic side chains within a disordered structure are critical for transcription and transforming activity of EWS family oncoproteins," Proceedings of the National Academy of Sciences of the United States of America, vol. 104, no. 2, pp. 479-484, 2007.

[73] A. Arvand, S. M. Welford, M. A. Teitell, and C. T. Denny, "The cooh-terminal domain of FLI-1 is necessary for full tumorigenesis and transcriptional modulation by EWS/FLI11,2," Cancer Research, vol. 61, no. 13, pp. 5311-5317, 2001.

[74] S. M. Welford, S. P. Hebert, B. Deneen, A. Arvand, and C. T. Denny, "DNA binding domain-independent pathways are involved in EWS/FLI1-mediated oncogenesis," The Journal of Biological Chemistry, vol. 276, no. 45, pp. 41977-41984, 2001.

[75] R. Li, H. Pei, and D. K. Watson, "Regulation of Ets function by protein-protein interactions," Oncogene, vol. 19, no. 55, pp. 6514-6523, 2000.

[76] H. V. Erkizan, V. N. Uversky, and J. A. Toretsky, "Oncogenic partnerships: EWS-FLI1 protein interactions initiate key pathways of Ewing's sarcoma," Clinical Cancer Research, vol. 16, no. 16, pp. 4077-4083, 2010.
[77] A. Varki, R. D. Cummings, J. D. Esko et al., Essentials of Glycobiology, Cold Spring Harbor Laboratory Press, Cold Spring Harbor, NY, USA, 2nd edition, 2009.

[78] K. A. W. Lee, "Ewings family oncoproteins: drunk, disorderly and in search of partners," Cell Research, vol. 17, no. 4, pp. 286-288, 2007.

[79] W. A. May, S. L. Lessnick, B. S. Braun et al., "The Ewing's sarcoma EWS/FLI-1 fusion gene encodes a more potent transcriptional activator and is a more powerful transforming gene than FLI- 1," Molecular and Cellular Biology, vol. 13, no. 12, pp. 7393-7398, 1993.

[80] W. A. May, M. L. Gishizky, S. L. Lessnick et al., "Ewing sarcoma 11;22 translocation produces a chimeric transcription factor that requires the DNA-binding domain encoded by FLI1 for transformation," Proceedings of the National Academy of Sciences of the United States of America, vol. 90, no. 12, pp. 5752-5756, 1993.

[81] S. L. Lessnick, B. S. Braun, C. T. Denny, and W. A. May, "Multiple domains mediate transformation by the Ewing's sarcoma EWS/FLI-1 fusion gene," Oncogene, vol. 10, no. 3, pp. 423-431, 1995.

[82] F. Nakatani, K. Tanaka, R. Sakimura et al., "Identification of p21WAF1/CIP1 as a direct target of EWS-Fli1 oncogenic fusion protein," The Journal of Biological Chemistry, vol. 278, no. 17, pp. 15105-15115, 2003.

[83] B. Fuchs, C. Y. Inwards, and R. Janknecht, "Upregulation of the matrix metalloproteinase-1 gene by the Ewing's sarcoma associated EWS-ER81 and EWS-Fli-1 oncoproteins, c-Jun and p300," FEBS Letters, vol. 553, no. 1-2, pp. 104-108, 2003.

[84] R. Smith, L. A. Owen, D. J. Trem et al., "Expression profiling of EWS/FLI identifies NKX2.2 as a critical target gene in Ewing's sarcoma," Cancer Cell, vol. 9, no. 5, pp. 405-416, 2006.

[85] L. A. Owen, A. A. Kowalewski, and S. L. Lessnick, "EWS/FLI mediates transcriptional repression via NKX2.2 during oncogenic transformation in Ewing's sarcoma," PLoS One, vol. 3, no. 4, Article ID e1965, 2008.

[86] L. L. Knoop and S. J. Baker, "The splicing factor U1C represses EWS/FLI-mediated transactivation,” The Journal of Biological Chemistry, vol. 275, no. 32, pp. 24865-24871, 2000.

[87] H. A. Chansky, M. Hu, D. D. Hickstein, and L. Yang, "Oncogenic TLS/ERG and EWS/Fli-1 fusion proteins inhibit RNA splicing mediated by YB-1 protein," Cancer Research, vol. 61, no. 9, pp. 3586-3590, 2001.

[88] Y. Muto, D. P. Krummel, C. Oubridge et al., "The structure and biochemical properties of the human spliceosomal protein U1C," Journal of Molecular Biology, vol. 341, no. 1, pp. 185-198, 2004.

[89] J. T. Zilfou and S. W. Lowe, "Tumor suppressive functions of p53," Cold Spring Harbor Perspectives in Biology, vol. 1, no. 5, Article ID a001883, 2009.

[90] P. Ozenne, B. Eymin, E. Brambilla, and S. Gazzeri, “The ARF tumor suppressor: structure, functions and status in cancer," International Journal of Cancer, vol. 127, no. 10, pp. 22392247, 2010.

[91] Q. Lin, X. Cong, and Z. Yun, "Differential hypoxic regulation of hypoxia-inducible factors $1 \alpha$ and $2 \alpha$," Molecular Cancer Research, vol. 9, no. 6, pp. 757-765, 2011.

[92] X. Lu and Y. Kang, "Hypoxia and hypoxia-inducible factors: master regulators of metastasis," Clinical Cancer Research, vol. 16, no. 24, pp. 5928-5935, 2010.

[93] M. C. Brahimi-Horn, G. Bellot, and J. Pouysségur, "Hypoxia and energetic tumour metabolism," Current Opinion in Genetics and Development, vol. 21, no. 1, pp. 67-72, 2010. 
[94] K. M. A. Rouschop, T. Van Den Beucken, L. Dubois et al., "The unfolded protein response protects human tumor cells during hypoxia through regulation of the autophagy genes MAP1LC3B and ATG5," The Journal of Clinical Investigation, vol. 120, no. 1, pp. 127-141, 2010.

[95] J. T. Erler, C. J. Cawthorne, K. J. Williams et al., "Hypoxiamediated down-regulation of bid and bax in tumors occurs via hypoxia-inducible factor 1-dependent and -independent mechanisms and contributes to drug resistance," Molecular and Cellular Biology, vol. 24, no. 7, pp. 2875-2889, 2004.

[96] P. Vaupel and A. Mayer, "Hypoxia in cancer: significance and impact on clinical outcome," Cancer and Metastasis Reviews, vol. 26, no. 2, pp. 225-239, 2007.

[97] P. Francis, H. M. Namløs, C. Müller et al., "Diagnostic and prognostic gene expression signatures in 177 soft tissue sarcomas: hypoxia-induced transcription profile signifies metastatic potential," BMC Genomics, vol. 8, article 73, 2007.

[98] K. Takenaga, "Angiogenic signaling aberrantly induced by tumor hypoxia," Frontiers in Bioscience, vol. 16, no. 1, pp. 3148, 2011.

[99] M. Kilic, H. Kasperczyk, S. Fulda, and K. M. Debatin, "Role of hypoxia inducible factor-1 alpha in modulation of apoptosis resistance," Oncogene, vol. 26, no. 14, pp. 2027-2038, 2007.

[100] A. S. Martins, C. Mackintosh, D. Herrero Martín et al., "Insulin-like growth factor I receptor pathway inhibition by ADW742, alone or in combination with imatinib, doxorubicin, or vincristine, is a novel therapeutic approach in Ewing tumor," Clinical Cancer Research, vol. 12, no. 11, pp. 35323540, 2006.

[101] R. Schickel, B. Boyerinas, S. M. Park, and M. E. Peter, "MicroRNAs: key players in the immune system, differentiation, tumorigenesis and cell death," Oncogene, vol. 27, no. 45, pp. 5959-5974, 2008.

[102] M. I. Almeida, R. M. Reis, and G. A. Calin, "MicroRNA history: discovery, recent applications, and next frontiers," Mutation Research. In press.

[103] R. W. Carthew and E. J. Sontheimer, "Origins and mechanisms of miRNAs and siRNAs," Cell, vol. 136, no. 4, pp. 642655, 2009.

[104] B. N. Davis-Dusenbery and A. Hata, "MicroRNA in cancer: the involvement of aberrant microRNA biogenesis regulatory pathways," Genes and Cancer, vol. 1, no. 11, pp. 1100-1114, 2011.

[105] T. A. Farazi, J. I. Spitzer, P. Morozov, and T. Tuschl, "MiRNAs in human cancer," Journal of Pathology, vol. 223, no. 2, pp. 102-115, 2011.

[106] L. A. MacFarlane and P. R. Murphy, "MicroRNA: biogenesis, function and role in cancer," Current Genomics, vol. 11, no. 7, pp. 537-561, 2010.

[107] J. S. Wei, P. Johansson, Q. R. Chen et al., "MicroRNA profiling identifies cancer-specific and prognostic signatures in pediatric malignancies," Clinical Cancer Research, vol. 15, no. 17, pp. 5560-5568, 2009.

[108] S. Subramanian, W. O. Lui, C. H. Lee et al., "MicroRNA expression signature of human sarcomas," Oncogene, vol. 27, no. 14, pp. 2015-2026, 2008.

[109] A. L. Sarver, R. Phalak, V. Thayanithy, and S. Subramanian, "S-MED: sarcoma microRNA expression database," Laboratory Investigation, vol. 90, no. 5, pp. 753-761, 2010.

[110] J. Zhang, H. Guo, H. Zhang et al., "Putative tumor suppressor miR-145 inhibits colon cancer cell growth by targeting oncogene friend leukemia virus integration 1 gene," Cancer, vol. 117, no. 1, pp. 86-95, 2011.
[111] S. J. Kim, J. S. Oh, J. Y. Shin et al., "Development of microRNA-145 for therapeutic application in breast cancer," Journal of Controlled Release, vol. 155, no. 3, pp. 427-434, 2011.

[112] S. Wach, M. Hart, E. Nolte, J. Szczyrba, B. Wullich, and F. Graesser, "The ERG 3'-UTR is a target of miR-145 and expression patterns of ERG isoforms are altered in prostate cancer," in Proceedings of the 102nd Annual Meeting of the American Association for Cancer Research (AACR '11), Orlando, Fla, USA, April 2011.

[113] P. C. Hollenhorst, L. P. McIntosh, and B. J. Graves, "Genomic and biochemical insights into the specificity of ETS transcription factors," Annual Review of Biochemistry, vol. 80, pp. 437471, 2011.

[114] V. Subbiah and P. Anderson, “Targeted therapy of Ewing's sarcoma," Sarcoma, vol. 2011, Article ID 686985, 2011.

[115] K. Tanaka, T. Iwakuma, K. Harimaya, H. Sato, and Y. Iwamoto, "EWS-Fli1 antisense oligodeoxynucleotide inhibits proliferation of human Ewing's sarcoma and primitive neuroectodermal tumor cells," The Journal of Clinical Investigation, vol. 99, no. 2, pp. 239-247, 1997.

[116] J. A. Toretsky, Y. Connell, L. Neckers, and N. K. Bhat, "Inhibition of EWS-FLI-1 fusion protein with antisense oligodeoxynucleotides," Journal of Neuro-Oncology, vol. 31, no. 12, pp. 9-16, 1997.

[117] M. Ouchida, T. Ohno, Y. Fujimura, V. N. Rao, and E. S. P. Reddy, "Loss of tumorigenicity of Ewing's sarcoma cells expressing antisense RNA to EWS-fusion transcripts," Oncogene, vol. 11, no. 6, pp. 1049-1054, 1995.

[118] H. Kovar, D. N. T. Aryee, G. Jug et al., "EWS/FLI-1 antagonists induce growth inhibition of Ewing tumor cells in vitro," Cell Growth and Differentiation, vol. 7, no. 4, pp. 429437, 1996.

[119] T. Dohjima, T. Ohno, Y. Banno, Y. Nozawa, Y. Wen-Yi, and K. Shimizu, "Preferential down-regulation of phospholipase C- $\beta$ in Ewing's sarcoma cells transfected with antisense EWSFli-1," British Journal of Cancer, vol. 82, no. 1, pp. 16-19, 2000.

[120] Y. Matsumoto, K. Tanaka, F. Nakatani, T. Matsunobu, S. Matsuda, and Y. Iwamoto, "Downregulation and forced expression of EWS-Fli1 fusion gene results in changes in the expression of G1 regulatory genes," British Journal of Cancer, vol. 84, no. 6, pp. 768-775, 2001.

[121] S. Asami, M. Chin, H. Shichino et al., “Treatment of Ewing's sarcoma using an antisense oligodeoxynucleotide to regulate the cell cycle," Biological and Pharmaceutical Bulletin, vol. 31, no. 3, pp. 391-394, 2008.

[122] A. Prieur, F. Tirode, P. Cohen, and O. Delattre, "EWS/FLI-1 silencing and gene profiling of Ewing cells reveal downstream oncogenic pathways and a crucial role for repression of insulin-like growth factor binding protein 3," Molecular and Cellular Biology, vol. 24, no. 16, pp. 7275-7283, 2004.

[123] I. Takigami, T. Ohno, Y. Kitade et al., "Synthetic siRNA targeting the breakpoint of EWS/Fli-1 inhibits growth of Ewing sarcoma xenografts in a mouse model," International Journal of Cancer, vol. 128, no. 1, pp. 216-226, 2011.

[124] T. Dohjima, N. S. Lee, H. Li, T. Ohno, and J. J. Rossi, "Small interfering RNAs expressed from a Pol III promoter suppress the EWS/Fli-1 transcript in an Ewing sarcoma cell line," Molecular Therapy, vol. 7, no. 6, pp. 811-816, 2003.

[125] H. A. Chansky, F. Barahmand-pour, Q. Mei et al., "Targeting of EWS/FLI-1 by RNA interference attenuates the tumor phenotype of Ewing's sarcoma cells in vitro," Journal of Orthopaedic Research, vol. 22, no. 4, pp. 910-917, 2004. 
[126] E. García-Aragoncillo, J. Carrillo, E. Lalli et al., "DAX1, a direct target of EWS/FLI1 oncoprotein, is a principal regulator of cell-cycle progression in Ewing's tumor cells," Oncogene, vol. 27, no. 46, pp. 6034-6043, 2008.

[127] S. Nozawa, T. Ohno, Y. Banno et al., "Inhibition of plateletderived growth factor-induced cell growth signaling by a short interfering RNA for EWS-Fli1 via down-regulation of phospholipase D2 in Ewing sarcoma cells," The Journal of Biological Chemistry, vol. 280, no. 30, pp. 27544-27551, 2005.

[128] J. Carrillo, E. García-Aragoncillo, D. Azorín et al., "Cholecystokinin down-regulation by RNA interference impairs Ewing tumor growth," Clinical Cancer Research, vol. 13, no. 8, pp. 2429-2440, 2007.

[129] S. Hu-Lieskovan, J. D. Heidel, D. W. Bartlett, M. E. Davis, and T. J. Triche, "Sequence-specific knockdown of EWS-FLI1 by targeted, nonviral delivery of small interfering RNA inhibits tumor growth in a murine model of metastatic Ewing's sarcoma," Cancer Research, vol. 65, no. 19, pp. 8984-8992, 2005.

[130] G. Lambert, J. R. Bertrand, E. Fattal et al., "EWS Fli-1 antisense nanocapsules inhibits Ewing sarcoma-related tumor in mice," Biochemical and Biophysical Research Communications, vol. 279, no. 2, pp. 401-406, 2000.

[131] H. Elhamess, J. R. Bertrand, J. MacCario, A. Maksimenko, and C. Malvy, "Antitumor vectorized oligonucleotides in a model of ewing sarcoma: unexpected role of nanoparticles," Oligonucleotides, vol. 19, no. 3, pp. 255-264, 2009.

[132] N. Toub, J. R. Bertrand, C. Malvy, E. Fattal, and P. Couvreur, "Antisense oligonucleotide nanocapsules efficiently inhibit EWS-Fli1 expression in a Ewing's sarcoma model," Oligonucleotides, vol. 16, no. 2, pp. 158-168, 2006.

[133] S. Mateo-Lozano, P. C. Gokhale, V. A. Soldatenkov, A. Dritschilo, O. M. Tirado, and V. Notario, "Combined transcriptional and translational targeting of EWS/FLI-1 in Ewing's sarcoma," Clinical Cancer Research, vol. 12, no. 22, pp. 6781-6790, 2006.

[134] D. Grimm, K. L. Streetz, C. L. Jopling et al., "Fatality in mice due to oversaturation of cellular microRNA/short hairpin RNA pathways," Nature, vol. 441, no. 7092, pp. 537-541, 2006.

[135] O. Awad, J. T. Yustein, P. Shah et al., "High ALDH activity identifies chemotherapy-resistant Ewing's sarcoma stem cells that retain sensitivity to EWS-Fli1 inhibition," PLoS One, vol. 5, no. 11, Article ID e13943, 2010.

[136] S. Rahim, E. M. Beauchamp, Y. Kong, M. L. Brown, J. A. Toretsky, and A. Üren, "YK-4-279 inhibits ERG and ETV1 mediated prostate cancer cell invasion," PLoS One, vol. 6, no. 4, 2011.

[137] W. R. Wilson and M. P. Hay, "Targeting hypoxia in cancer therapy," Nature Reviews Cancer, vol. 11, no. 6, pp. 393-410, 2011.

[138] R. G. Maki, A. S. Kraft, K. Scheu et al., "A multicenter phase II study of bortezomib in recurrent or metastatic sarcomas," Cancer, vol. 103, no. 7, pp. 1431-1438, 2005.

[139] T. Nakamura, K. Tanaka, T. Matsunobu et al., "The mechanism of cross-resistance to proteasome inhibitor bortezomib and overcoming resistance in Ewing's family tumor cells," International Journal of Oncology, vol. 31, no. 4, pp. 803-811, 2007.

[140] A. Abudu, D. C. Mangham, G. M. Reynolds et al., "Overexpression of p53 protein in primary Ewing's sarcoma of bone: relationship to tumour stage, response and prognosis," British Journal of Cancer, vol. 79, no. 7-8, pp. 1185-1189, 1999.
[141] H. Y. Huang, P. B. Illei, Z. Zhao et al., "Ewing sarcomas with p53 mutation or p16/p14ARF homozygous deletion: a highly lethal subset associated with poor chemoresponse," Journal of Clinical Oncology, vol. 23, no. 3, pp. 548-558, 2005.

[142] L. Dauphinot, C. De Oliveira, T. Melot et al., "Analysis of the expression of cell cycle regulators in Ewing cell lines: EWSFLI-1 modulates p57KIP2 and c-Myc expression," Oncogene, vol. 20, no. 25, pp. 3258-3265, 2001.

[143] J. Joo, L. Christensen, K. Warner et al., "GLI1 is a central mediator of EWS/FLI1 signaling in Ewing Tumors," PLoS One, vol. 4, no. 10, Article ID e7608, 2009.

[144] O. M. Tirado, S. Mateo-Lozano, J. Villar et al., "Caveolin-1 (CAV1) is a target of EWS/FLI-1 and a key determinant of the oncogenic phenotype and tumorigenicity of Ewing's sarcoma cells," Cancer Research, vol. 66, no. 20, pp. 9937-9947, 2006.

[145] C. Siligan, J. Ban, R. Bachmaier et al., "EWS-FLI1 target genes recovered from Ewing's sarcoma chromatin," Oncogene, vol. 24, no. 15, pp. 2512-2524, 2005. 


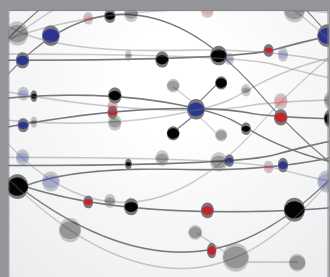

The Scientific World Journal
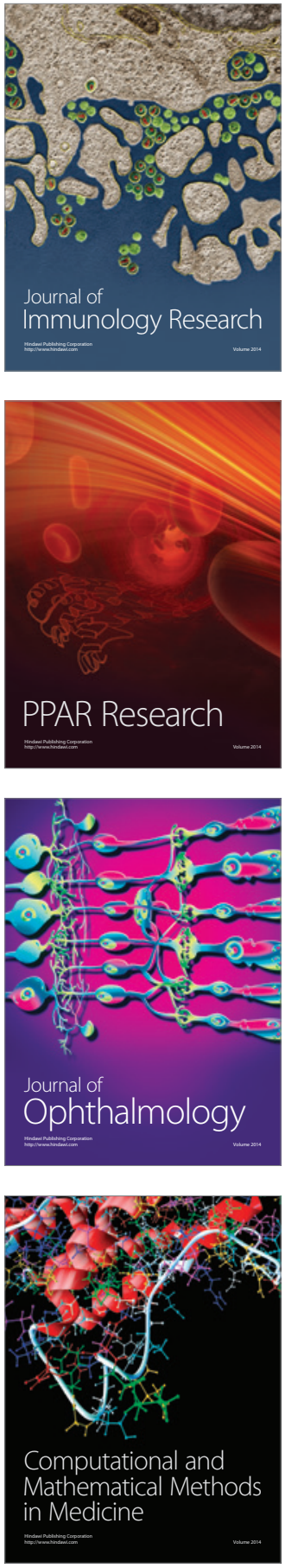

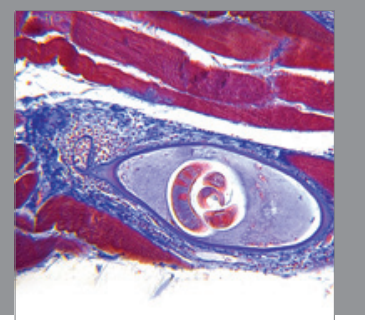

Gastroenterology

Research and Practice
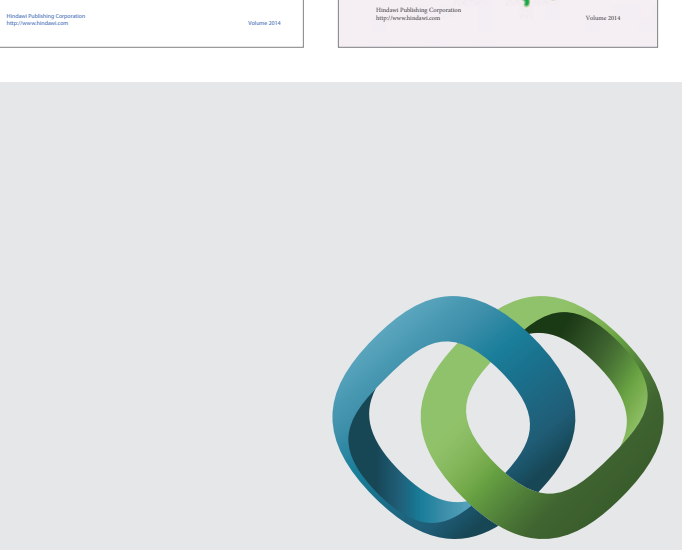

\section{Hindawi}

Submit your manuscripts at

http://www.hindawi.com
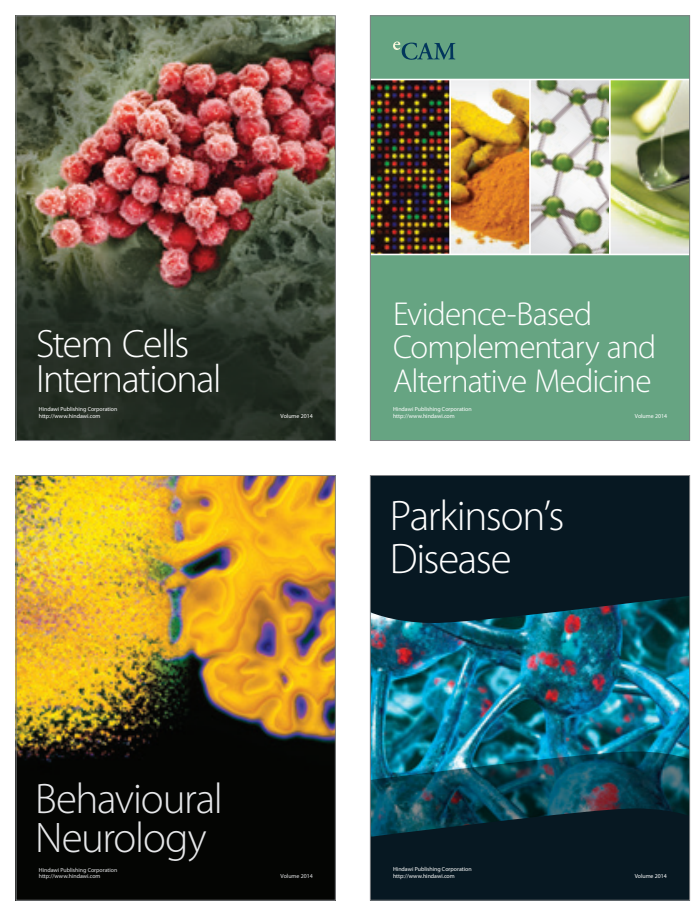

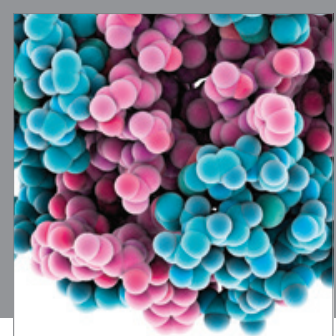

Journal of
Diabetes Research

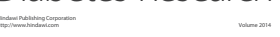

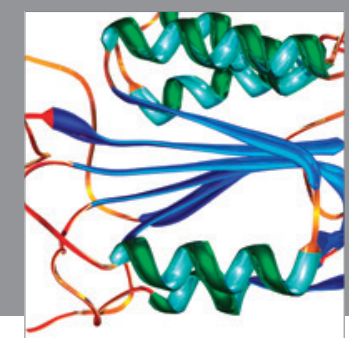

Disease Markers
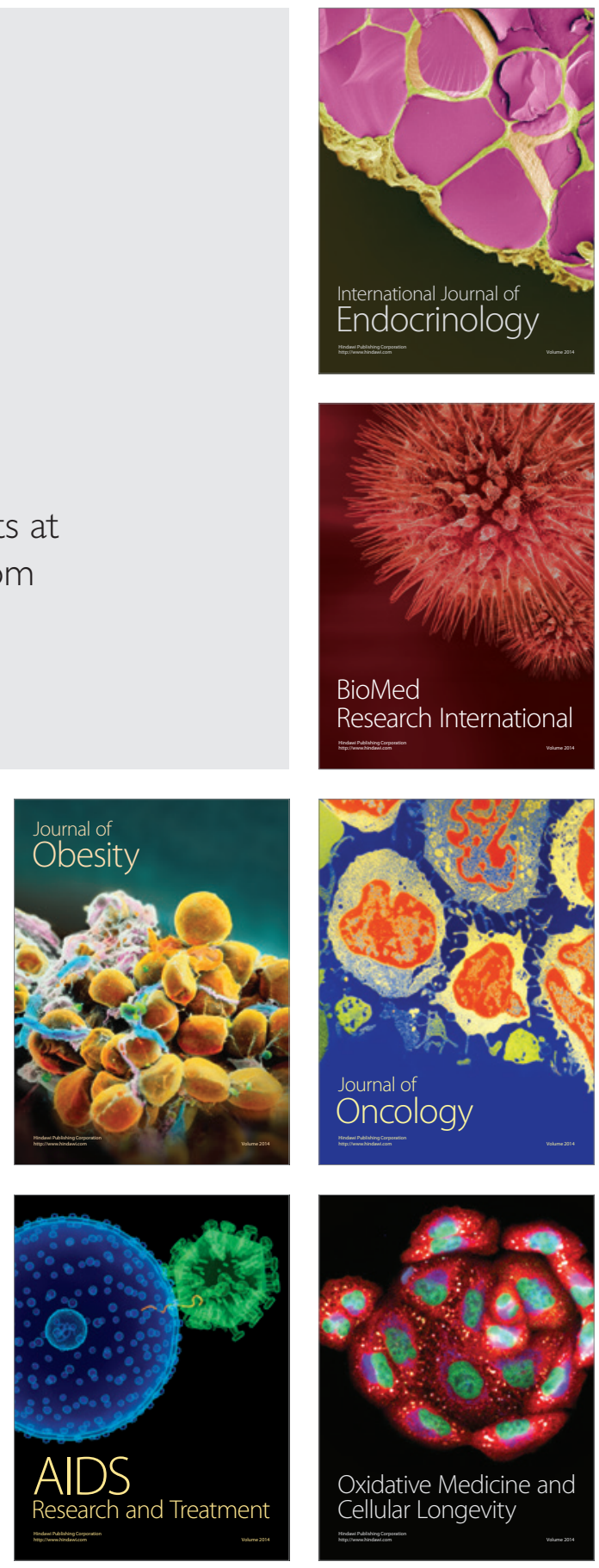